\title{
As ciências da natureza em manuais didáticos de filosofia
}

\author{
Margarethe Steinberger-Elias (UFABC)
}

Francisco das Chagas Pereira (UFABC)

\section{RESUMO-PÔSTER}

Este trabalho faz parte de um projeto mais amplo sobre a linguagem e a comunicação nos manuais didáticos de ciências. Aqui o objetivo é apresentar resultado preliminar de um estudo sobre paráfrases utilizadas em manuais de ensino de Filosofia recomendados oficialmente para o ensino médio na rede pública brasileira. Paráfrases são formas variadas de formular explicações, definições e exemplificações. O foco do trabalho são os conceitos de "natureza" e de "ciências da natureza" no âmbito de uma história do pensamento filosófico sobre as ciências. Foram selecionados trechos de cinco manuais didáticos que abordam estes conceitos, de modo a caracterizar o papel das paráfrases como recurso facilitador da compreensão textual. A metodologia adotada revelou que o uso dos termos "natureza" e "ciências da natureza" envolve não só processos parafrásticos (modos de expressão variados de produzir o sentido dos termos estudados), mas também processos polissêmicos (múltiplos sentidos para um mesmo termo). 0 trabalho discute estes primeiros resultados e suas implicações no sentido de facilitar ou dificultar as atividades de leitura no ensino de ciências. 